\title{
DEVELOPMENT OF AN ONLINE DATABASE FOR DIPHTHERIA MOLECULAR EPIDEMIOLOGY UNDER THE REMIT OF THE DIPNET PROJECT
}

T Dallman ${ }^{1}$, S Neal ${ }^{2}$, J Green (jonathan.green@hpa.org.uk) ${ }^{1}$, A Efstratiou ${ }^{2}$

1. Bioinformatics, Centre for Infections, Heath Protection Agency, London, United Kingdom

2. Respiratory and Systemic Infection Laboratory, Centre for Infections, Heath Protection Agency, London, United Kingdom

The Diphtheria Surveillance Network (DIPNET), launched on 1 November 2006, is a 38-month programme bringing together 25 European Union partner countries (24 Member States and Turkey) and collaborating countries beyond Europe in a global dedicated surveillance network for diphtheria and related infections caused by Corynebacterium diphtheriae and C. ulcerans [1].

Despite the success of mass immunisation, epidemic diphtheria re-emerged in the early 1990s in Russia and the newly independent states of the former Union of Soviet Socialist Republics [2,3]. The European Laboratory Working Group on Diphtheria (ELWGD) was created in 1993 in response to this crisis at the request of the World Health Organization Regional Office for Europe (WHO Europe) [4]. One of the objectives of this collaborative effort was to establish a standard genotyping method for rapid tracking of strains. Since then, several new molecular subtyping methods have been developed, such as ribotyping, pulsed-field gel electrophoresis (PFGE), multilocus enzyme electrophoresis (MEE), random amplification of polymorphic DNA (RAPD) and amplified fragment length polymorphisms (AFLP), and all have been applied to epidemiological investigations of diphtheria, with largely successful results [5-8].

The application of standardised molecular epidemiological tools is essential for monitoring the spread of epidemic clones and to allow for the distinction between epidemic, endemic and imported cases. This also has major implications for timely and adequate preventative measures. Although excellent progress has been made in reducing the diphtheria incidence within the WHO European Regions, several countries such as Belarus, Georgia, the Russian Federation and Ukraine are still experiencing problems [9]. Of particular concern is that in 2006, Latvia experienced a relatively high diphtheria incidence of 1.39 per 100,000 population compared to 0.13 per 100,000 in Russia [personal communication Irina Lucenko]. With this in mind, several basic questions need to be addressed. Could strains associated with the previous European epidemic be differentiated from all other strains currently circulating worldwide? What was it that enabled these strains to cause an epidemic of such proportions within the former Soviet Union? Are we dealing with new, more virulent strains? Has the toxin changed in such a way that the current vaccine may be ineffective?
Molecular subtyping therefore plays a major role in providing the answers to some of these questions. Ribotyping has been evaluated as a discriminatory method for subtyping diphtheria strains and has since been used as the 'gold standard' by several groups. Ribotyping methods have been standardised and disseminated to other centres, and an international nomenclature for $C$. diphtheriae ribotypes has been agreed [10]. A database of ribotype patterns has also been established at the Institut Pasteur, Paris, France, using the software programme Taxotron [10]. Currently, there are 86 ribotypes from 576 strains in the database, and new ribotypes are validated at the Institut Pasteur before designation. In this collection, ribotypes Sankt-Petersburg and Rossija (previously G1 and G4, respectively) were the predominant strains circulating in the Russian epidemic [5]. Definitive and extensive improvements need to be undertaken to enable more rapid and accurate detection of these 'clones' globally, with the establishment of an online international database for automatic, real-time recognition of genotypes.

A key component of DIPNET is an online database providing access to integrated case, epidemiological and genotyping data. The DIPNET website (http://www.dipnet.org) will provide a portal for the DIPNET participants to query and analyse this data. This online surveillance database allows patient, clinical and laboratory data to be integrated with associated immunisation, travel, and case and contact management epidemiological data. Furthermore the database can be securely accessed, updated and modified online in real-time by disparately located participants.

The surveillance database is further underpinned by linking molecular typing results to the ribotype reference strain database. A database of 'reference ribotype patterns' has been integrated into the Bionumerics platform, and automated assignment of ribotypes, through the uploading of ribotype gel-profiles, has been facilitated. This will allow DIPNET participants to analyse the patient, epidemiological and genotyping data simultaneously.

Portability and reproducibility often pose challenges with gel based genotyping methods. Therefore the ribotype strain database will be developed significantly to explore the correlation between more novel, rapid and accessible methodologies such as multilocus sequence typing (still under development) and other new sequencebased methodologies. 
Retrospective surveillance data from participating countries collected over the period 2000-2005 on all laboratory-confirmed cases of non-toxigenic and toxigenic strains is being integrated initially. This will then be supplemented by the implementation of a web interface that will allow automated uploading of current case data, expected to go live in June 2008. These data will be subject to agreed data quality standards and formats modelled on the reporting system used by WHO/Europe, but enhanced to incorporate reporting for toxigenic $C$. ulcerans and non-toxigenic infections, with the aim of linking to the ECDC reporting system.

The outputs from this project will enable countries to readdress their strategies for diphtheria and related infections and will establish defined and standardised mechanisms for public health and microbiological surveillance. It is envisaged that the DIPNET online diphtheria genotyping database will attract global users, thus improving communication, standardising genotypes and understanding of the spread of diphtheria.

\section{Acknowledgments}

This work was supported by the European Commission, DG SANCO agreement number 2005210.

\section{References}

1. Neal S, Efstratiou A. DIPNET - establishment of a dedicated surveillance network for diphtheria in Europe. EuroSurveill. 2007; 12(12):E9-E10.

2. Galazka AM, Robertson SE. Diphtheria: changing patterns in the developing world and the industrialized world. Eur J Epidemiol. 1995;11(1):107-17.

3. Dittmann S. Epidemic diphtheria in the Newly Independent States of the former USSR--situation and lessons learned. Biologicals. 1997;25(2):179-86.

4. Efstratiou A, Roure C. The European Laboratory Working Group on Diphtheria: A global microbiologic network. J Infect Dis. 2000;181(Suppl 1):S146-51.

5. De Zoysa A, Efstratiou A, George RC, Jahkola M, Vuopio-Varkila J, Deshevoi $S$, et al. Molecular epidemiology of Corynebacterium diphtheriae from northwestern Russia and surrounding countries studied by using ribotyping and pulsed-field gel electrophoresis. J Clin Microbiol. 1995;33(5):1080-3.

6. Popovic T, Kombarova SY, Reeves MW, Nakao H, Mazurova IK, Wharton M, et al. Molecular epidemiology of diphtheria in Russia, 1985-1994. J Infect Dis. 1996;174(5):1064-72.

7. De Zoysa AS, Efstratiou A. PCR typing of Corynebacterium diphtheriae by random amplification of polymorphic DNA. J Med Microbiol. 1999;48(4):335-40.

8. De Zoysa A, Efstratiou A. Use of amplified fragment length polymorphisms for typing Corynebacterium diphtheriae. J Clin Microbiol. 2000;38(10):3843-5.

9. Spika J, Emiroglu N. Current status of diphtheria in the European Region of WHO. In: Programme and Abstracts Book, Ninth International Meeting of the European Laboratory Working Group on Diphtheria and Diphtheria Surveillance Network; 2006 15-17 Nov; Vouliagmeni, Greece. P.35.

10. Grimont PA, Grimont F, Efstratiou A, De Zoysa A, Mazurova I, Ruckly C, et al. International nomenclature for Corynebacterium diphtheriae ribotypes. Res Microbiol. 2004;155(3):162-6.

This article was published on 8 May 2008.

Citation style for this article: Dallman T, Neal S, Green J, Efstratiou A. Development of an online database for diphtheria molecular epidemiology under the remit of the DIPNET project . Euro Surveill. 2008;13(19):pii=18865. Available online: http://www. eurosurveillance.org/ViewArticle. aspx?ArticleId=18865 